\title{
A Randomized, Double-Blind, Placebo- \\ Controlled Study to Test the Efficacy of Topical 2-Hydroxypropyl-Beta-Cyclodextrin in the Prophylaxis of Recurrent Herpes Labialis
}

\author{
Gabriela Senti $^{\mathrm{a}}$ Reto lannaccone $^{\mathrm{a}}$ Nicole Graf ${ }^{\mathrm{a}}$ Manuela Felder ${ }^{\mathrm{a}}$ Fabian Tay $^{\mathrm{a}}$ \\ Thomas Kündig ${ }^{b}$ \\ ${ }^{a}$ Clinical Trials Center and ${ }^{b}$ Division of Dermatology, University Hospital Zurich, Zurich, Switzerland
}

\section{Key Words}

Herpes labialis · 2-Hydroxypropyl- $\beta$-cyclodextrin · Antiviral compound $\cdot$ Prophylactic treatment $\cdot$ Topical application

\begin{abstract}
Herpes labialis affects one third of the population. We evaluated the topical application of an antiviral compound, hydroxypropyl- $\beta$-cyclodextrin (2-HP $\beta C D)$, in reducing herpes labialis relapses. In this double-blind, randomized, placebo-controlled trial, 40 patients were randomized to a polyethylene glycol (PEG) formulation containing 20\% 2-HPßCD or to a vehicle control arm. The gel was applied to the lips twice daily for 6 months. The primary objective was reducing herpes relapses. Surprisingly, the drug group had significantly more relapses than the vehicle group $(p=0.003)$. While the median numbers of relapses in the preceding year were 12 in the vehicle group and 10 in the drug group, both groups experienced very few relapses during the 6-month treatment period, with a median of 0 in the vehicle group and a median of 2 in the drug group. The impressive reduction of relapses in both groups may be due to a placebo effect or due to the topical treatment with PEG.
\end{abstract}

Copyright $\odot 2013$ S. Karger AG, Basel

\begin{tabular}{|c|c|}
\hline KARGER & $\begin{array}{l}\text { (c) } 2013 \text { S. Karger AG, Basel } \\
1018-8665 / 13 / 2263-0247 \$ 38.00 / 0\end{array}$ \\
\hline $\begin{array}{l}\text { E-Mail karger@karger.com } \\
\text { www.karger.com/drm }\end{array}$ & $\begin{array}{l}\text { This is an Open Access article licensed under the terms of the } \\
\text { Creative Commons Attribution-NonCommercial 3.0 Un- } \\
\text { ported license (CC BY-NC) (www.karger.com/OA-license), } \\
\text { applicable to the online version of the article only. Distribu- } \\
\text { tion permitted for non-commercial purposes only. }\end{array}$ \\
\hline
\end{tabular}

\section{Introduction}

Herpes labialis or orolabial herpes is an infection of the lip with herpes simplex virus (HSV). In the USA, the lifetime prevalence of recurrent herpes labialis is estimated at $20-40 \%$ with approximately 100 million episodes occurring in the country every year [1]. The lifetime prevalence in Europe is estimated at approximately $30 \%$ [2]. A number of antiviral agents are available for the treatment of herpes labialis. Widely used is acyclovir, a nucleoside analogue of the guanine base. In recent years, a growing number of viruses became resistant against acyclovir, which is a problem of increasing clinical significance in immunocompromised patients [3]. It has been demonstrated that beta-cyclodextrin was able to reduce the titer of acyclovir-resistant viruses, thus suggesting a different mode of action [4]. It could be shown that the depletion of cholesterol of the HSV envelope with beta-cyclodextrin inhibited the ability of the virus to infect host cells up to $90 \%$ [5]. Another study demonstrated that the mechanism of cholesterol depletion

G. Senti and R. lannaccone contributed equally to this work. 
was exerted also with 2-hydroxypropyl- $\beta$-cyclodextrin (2-HP $\beta C D)[6]$. The objective of this study was to investigate the efficacy of a prophylactic topical treatment with $2-\mathrm{HP} \beta \mathrm{CD}$ to reduce the number of herpes labialis relapses in humans.

\section{Materials and Methods}

\section{Study Design}

This double-blind, randomized, placebo-controlled trial was conducted at the Clinical Trials Center Zurich, Switzerland, after approval by the local ethics committee and Swissmedic. The study was conducted in accordance with the Declaration of Helsinki and the ICH Guidelines on Good Clinical Practice and was registered at ClinicalTrials.gov (NCT00914745). Between June and November 2009, 40 patients gave informed consent, were enrolled and randomly assigned $1: 1$ to either $2-\mathrm{HP} \beta \mathrm{CD} 20 \%$ gel or placebo. $\mathrm{Pa}-$ tients had to apply the gel to the lips twice daily for 6 months. In case of an acute relapse, patients were asked to come to the study site on days 1, 5, 10 and $14( \pm 24 \mathrm{~h})$ after start of the first signs and symptoms for confirmation and monitoring of the relapse. Furthermore, the patients had to record daily the level of pain on a visual analogue scale $(100 \mathrm{~mm})$ during the entire relapse time (14 days), which was subsequently measured as area under the curve (AUC). For a more precise description of the symptoms, patients had to determine the intensity of different prodromal signs such as tension, hypersensitivity, tingling, burning, and itching. During the entire study, patients had to record the applications into provided diaries to evaluate compliance of drug administration. The primary objective was to investigate the efficacy of HP $\beta$ CD $20 \%$ gel to reduce the number of herpes labialis relapses compared to placebo. Secondary objectives included the evaluation of the safety and tolerability of the HP $\beta$ CD $20 \%$ gel as well as the comparison of the maximal lesion area, the duration of the herpes relapse episodes and the degree of pain during a relapse episode between patients receiving HP $\beta C D 20 \%$ gel and placebo patients. The study remained blinded until after database lock.

\section{Product}

The study drug was composed of $20 \% 2-\mathrm{HP} \beta \mathrm{CD}$ dissolved in a mixture of various types of polyethylene glycols (PEGs) for active drug patients and a mixture of the same PEGs only for placebo patients. 2-HP $\beta C D$ was provided by Devirex AG, Switzerland. The drug and placebo PEG preparations were produced by the Cantonal Pharmacy Zurich according to Good Manufacturing Practice.

\section{Patients}

Patients were recruited via placards and newspaper advertisements and were included in the study if they were aged $18-50$ years and had experienced at least 8 herpes labialis relapses in the previous year. We excluded women with child-bearing potential who were not using a reliable method of birth control, pregnant or breastfeeding women, patients with a medical history of immunosuppression by radiotherapy, chemotherapy, immunomodulatory drugs, or HIV, patients participating in another clinical study, patients with a medical history of any severe disease like hepatitis,
Table 1. Demographic and other baseline characteristics by treatment group and for patients included in the efficacy analysis

\begin{tabular}{|c|c|c|}
\hline \multirow[t]{2}{*}{ Characteristics } & \multicolumn{2}{|c|}{ Treatment group } \\
\hline & $\begin{array}{l}\text { placebo } \\
(\mathrm{n}=15)\end{array}$ & $\begin{array}{l}2-\mathrm{HP} \beta C D \\
(\mathrm{n}=18)\end{array}$ \\
\hline Mean age $\pm S D$, years & $35.5 \pm 11.3$ & $32.6 \pm 9.1$ \\
\hline Female, $\mathrm{n}(\%)$ & $11(73.3)$ & $13(72.2)$ \\
\hline \multicolumn{3}{|l|}{ Race, n (\%) } \\
\hline Caucasian & $15(100.0)$ & $17(94.4)$ \\
\hline Asian & $0(0)$ & $1(5.6)$ \\
\hline Mean duration of disease $\pm \mathrm{SD}$, years & $24.7 \pm 10.7$ & $21.3 \pm 11.9$ \\
\hline $\begin{array}{l}\text { Mean number of relapses in the } \\
\text { preceding year } \pm \text { SD }\end{array}$ & $12.7 \pm 3.9$ & $10.9 \pm 2.3$ \\
\hline
\end{tabular}

cardiovascular or gastrointestinal disease, renal or liver dysfunction, malignancies, or psychiatric disorder, patients using antiviral drugs, systemic anti-inflammatory medications or steroids, patients suffering from eczema herpeticatum or any abnormal perioral skin condition.

\section{Statistics}

Effectiveness of 2-HP $\beta C D$ was assumed to be comparable to acyclovir. The sample size was calculated with nQuery Advisor 7.0 based on published data on acyclovir [7]. It was assumed that the mean number $( \pm \mathrm{SD})$ of recurrences within 30 days is $1.8( \pm 0.65)$ for the placebo group and $0.85( \pm 0.3)$ for the active treatment group. With a sample size of 12 per group $(\mathrm{n}=24$ in total), the study would have a power of $90 \%$ to yield a statistically significant result $(\alpha=0.05)$ in a Mann-Whitney test. To compensate for dropouts (estimated $40 \%$ ), a total of 40 patients were needed. The statistical analyses of the data were performed by using Wilcoxon signed-rank tests (intragroup comparisons) or Mann-Whitney tests (intergroup comparisons). All calculations were done in PASW Statistics 18.

\section{Results}

A total of 46 subjects were screened of which 6 did not meet the inclusion or exclusion criteria. A total of $20 \mathrm{pa}-$ tients were randomized to each of the two treatment groups. During the course of the study, 2 patients in the 2 -HP $\beta C D$ group withdrew consent. In the placebo group, 1 patient was lost to follow-up, 1 patient was excluded after 2 days of study participation due to an adverse event (strong perioral pruritus already after first application), 1 patient was excluded because of lack of compliance and 2 patients withdrew consent (fig. 1 ).

The two treatment groups did not differ in basic demographic or other baseline characteristics (table 1). 


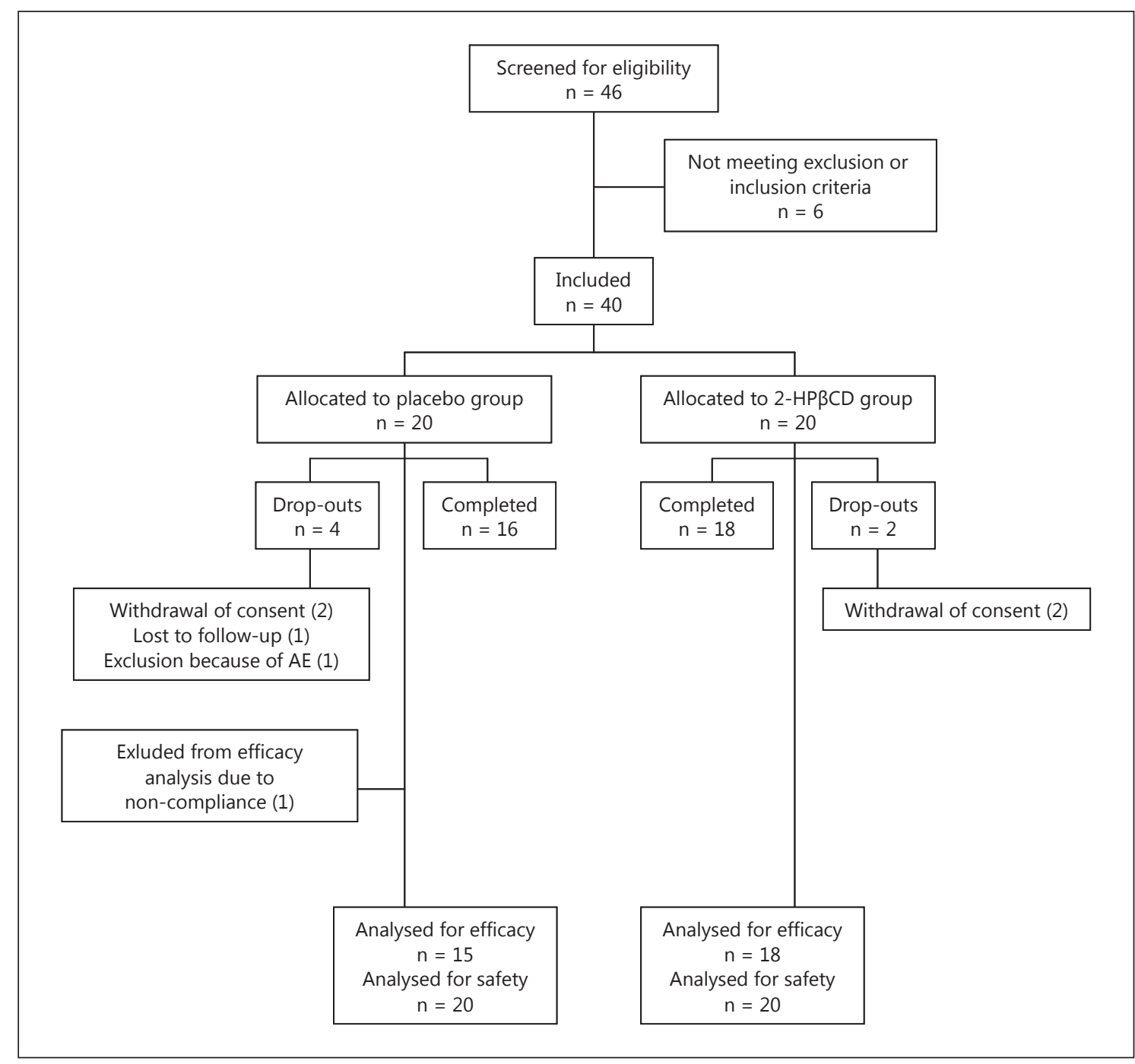

Fig. 1. Flow chart with numbers of patients screened, randomized, treated, and analysed. AE = Adverse event.

With 24 women $(72.7 \%)$ and 9 men $(27.3 \%)$, the sample analysed for efficacy comprised more female than male patients.

Unexpectedly, the 2-HP $\beta C D$ group experienced significantly more herpes labialis relapses than the placebo group (Mann-Whitney test, $\mathrm{p}=0.003$ ). During the 6 months of treatment however, both treatment groups experienced very few relapses with a median number of relapses between 0 (placebo group) and $2(2-\mathrm{HP} \beta \mathrm{CD}$ group) compared to a reported median number of relapses between 12 (placebo group) and 10 (2-HP $\beta \mathrm{CD}$ group) in the preceding year (fig. 2). In the placebo group, $80 \%$ of all patients experienced a relative reduction of relapses between 75 and 100\% (fig. 3). The reduction of relapses was not as pronounced in the $2-\mathrm{HP} \beta \mathrm{CD}$ group, which was confirmed by the results of a Mann-Whitney test $(p=0.001)$.

All patients with at least 1 relapse were further analysed with respect to the mean size, duration and pain of the relapses. No differences could be shown between drug and placebo patients with respect to the maximal size and duration of the relapses. The drug group however experienced less pain than the placebo group. The AUC of the daily pain level was smaller in the drug group than in the placebo group (fig. 4), though not significantly ( $\mathrm{p}=$ $0.101)$. Correspondingly, the symptom severity was consistently higher in the placebo than in the drug group. The symptom scores were significantly higher for tingling $(\mathrm{p}=0.040)$, burning $(\mathrm{p}=0.028)$ and total symptoms $(\mathrm{p}=$ 


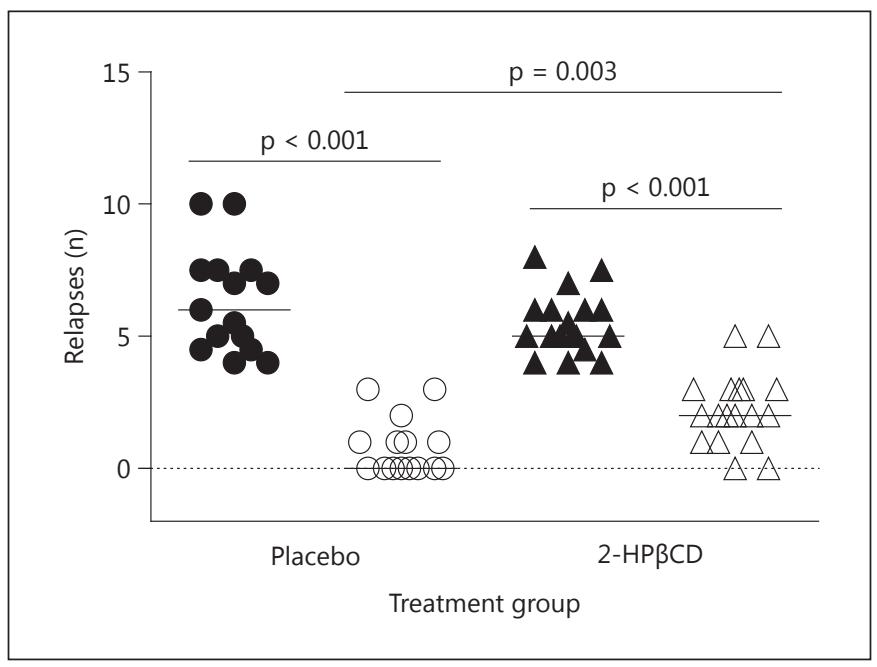

Fig. 2. Scatter dot plot showing the number of relapses in both treatment groups before treatment (filled symbols) and during treatment (open symbols). The number of herpes labialis relapses in the previous year before study start was divided by two for reasons of comparability. The intergroup comparison indicated that the drug group had significantly more herpes labialis relapses than the placebo group $(\mathrm{p}=0.003)$. Intragroup comparisons revealed that both groups experienced significantly fewer relapses during than before the study $(\mathrm{p}<0.001)$.

0.048 ), but not for tension ( $\mathrm{p}=0.156)$, hypersensitivity $(\mathrm{p}=0.119)$ and itching $(\mathrm{p}=0.283)$.

The study medication was generally well tolerated. The most common adverse events were headaches, colds, dry lips, burning sensation on the lips, and HSV relapses outside the perioral region. The treatment group did not have any influence on the frequency of drug-related adverse events. In the placebo group, 32 out of 117 adverse events $(27.4 \%)$ were classified as drug related; in the 2 -HP $\beta$ CD group, 32 out of 128 adverse events (24.8\%) were classified to be drug related. In the placebo group, $65.6 \%$ of all 32 drug-related adverse events were rated as mild, $25.0 \%$ as moderate and $9.4 \%$ as severe. In the 2 -HP $\beta C D$ group, $81.3 \%$ of the 32 adverse events were rated as mild, $15.6 \%$ as moderate and $3.1 \%$ as severe. The most frequent drug-related adverse events in both treatment groups affected the perioral region and were circumscribed as itching, tickling, or burning sensation on the lips, dry lips, and erythema.

Six months after study end, the patients were sent a follow-up questionnaire. Eleven patients from the placebo group and 12 patients from the drug group returned the questionnaire asking about the current situation of their herpes. Nearly half of all patients (48\%) experienced

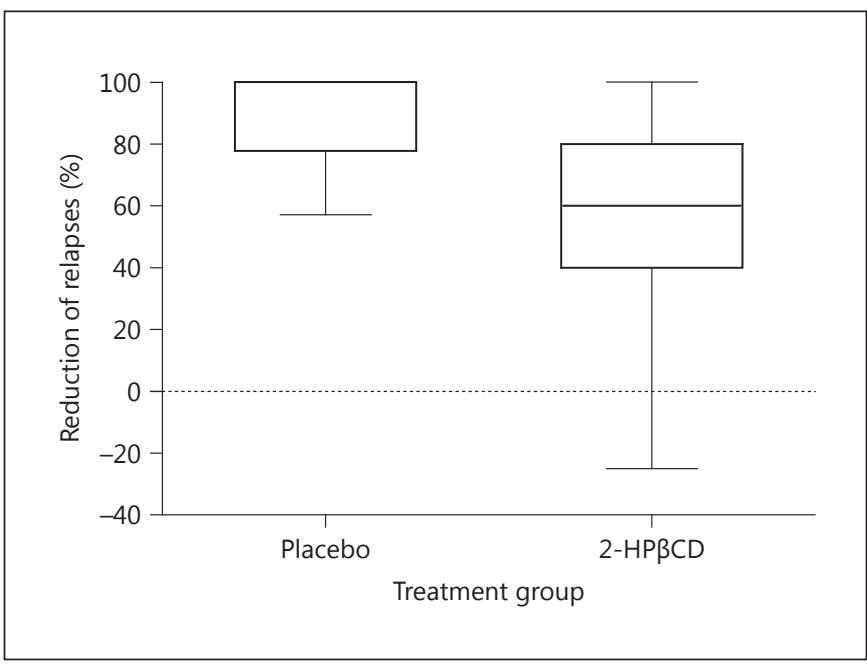

Fig. 3. Box plot showing the relative reduction of relapses during study treatment compared to the previous year for the placebo $(\mathrm{n}=15)$ and the 2 -HP $\beta C D$ groups $(n=18)$. Boxes show the 25 th, 50 th and 75 th percentiles and whiskers the minimum and maximum.

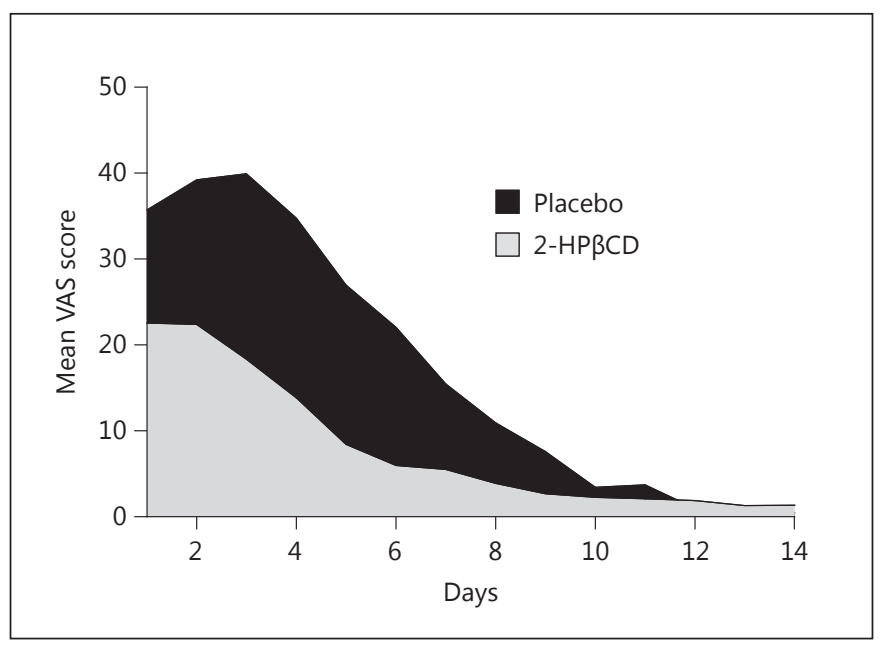

Fig. 4. The mean daily visual analogue scale (VAS) score during a herpes labialis relapse for the placebo $(n=7)$ and the drug group $(\mathrm{n}=16)$. The AUC of the daily pain level was smaller in the drug group than in the placebo group, though not significantly ( $\mathrm{p}=$ $0.101)$.

the first relapse 1-3 months after study end, while the other half (44\%) experienced the first relapse 3-6 months after study end or even later. There was no statistically significant difference between the two treatment groups (Mann-Whitney U test, $\mathrm{p}=0.222$ ). 


\section{Discussion}

2-HP $\beta C D$ proved safe, but not effective. The only positive finding was a reduction of pain during the herpes labialis episodes in the drug group compared to the placebo group. A possible reason for the ineffectiveness of 2 -HP $\beta C D$ could be its poor absorption. Irie and Uekama [8] could show that the percutaneous absorption of $2-\mathrm{HP} \beta \mathrm{CD}$, which was applied in an aqueous solution to the skin of hairless mice, was extremely low at approximately $0.02 \%$ after $24 \mathrm{~h}$ of topical application. The amount of 2 -HP $\beta \mathrm{CD}$ absorbed from the tape-stripped skin was approximately $24 \%$ suggesting that the stratum corneum acts as a barrier to the penetration of $2-\mathrm{HP} \beta \mathrm{CD}$ through the skin.

While 2-HP $\beta C D$ obviously could not reduce the number of herpes labialis recurrences, both treatment groups had surprisingly few herpes labialis recurrences during the study duration compared to the preceding year. Thus, both treatment groups had significantly fewer recurrences during the 6 months of study treatment compared to the time before the study $(\mathrm{p}<0.001$ for both treatment groups). Such a profound reduction of relapses appears too high to be explained solely by a placebo effect. In comparable studies using daily oral valacyclovir (500 $\mathrm{mg}$ ) versus placebo for the prevention of recurrent herpes labialis in patients with a history of 4 or more recurrent lesions in the previous year, only $60 \%$ in the valacyclovir group compared with $38 \%$ in the placebo group were recurrence free throughout the 4-month treatment period [9]. In the present study the number of recurrent lesions in the previous year was higher, with 12.7 in the placebo group and 10.9 in the drug group, respectively. Yet, during an even longer treatment period of 6 months, 8 out of 15 patients $(53 \%)$ remained relapse free, which is therefore comparable with published results on oral valacyclovir.

This suggests the possibility that the effect could also be due to the excipient PEG, also known as macrogol. PEG was applied twice daily to the lips, entirely covering them. Previous studies have demonstrated antiviral activities of saturated and unsaturated alcohols of moderate lengths $[10,11]$. Optimal antiviral activity was observed with saturated alcohols 10-12 carbons long but these compounds also exhibited cytotoxic and haemoly tic effects; less antiviral activity was observed with alcohols 1418 carbons long, and alcohols of higher chain lengths were not tested [10]. Studies with unsaturated alcohols and monoglycerides revealed peak activity with a triply double-bonded $\mathrm{C}_{18}$ alcohol [11]. Docosanol, also called behenyl alcohol, is a saturated fatty alcohol which is used as an emollient and emulsifier in topical products and which was found to exert antiviral activity [12]. Docosanol was approved by the Food and Drug Administration as a topical treatment of orolabial herpes $\left(\right.$ Abreva $^{\circledR}$, Erazaban $\left.^{(}\right)$. The mechanism of action is yet unknown. Current evidence suggests that docosanol inhibits viral replication by interfering with viral entry into target cells. Interaction between the highly lipophilic compound and the target cell membranes may inhibit viral fusion and/or entry [12].

PEG is widely used as an excipient in topical products. The findings of this study suggest that, similarly, PEG used in high concentration has antiviral activity. However, the exact mechanism is still unknown and subject to further investigations. PEGs, depending on their molecular weight, show variable penetration across the epidermis [13].

From a theoretical perspective topical antivirals should not be effective prophylactically because topical application will not get the drug to the site of reactivation [14]. However, when viral replication is inhibited early, recurrences may not become clinically apparent. In fact, a controlled trial showed that acyclovir/hydrocortisone cream significantly reduced the frequency of both ulcerative and non-ulcerative recurrences in immunocompetent adults and adolescents [15].

In summary, the present study could not demonstrate antiviral activity of 2-HP $\beta C D$ over placebo. Surprisingly, however, this study reveals a profound reduction of herpes labialis relapses in both, the placebo and the drug groups. This effect is likely attributed to PEG.

\section{Acknowledgement}

We thank Annette Widmann, Head Regulatory Affairs CTC, for helping with setting up the study.

\section{Disclosure Statement}

The study drug 2-HP $\beta C D$ was provided by Devirex AG, which was also the sponsor of the study. Apart from that, the authors declare that they have no conflicts of interest. 


\section{References}

$>1$ Young TB, Rimm EB, D’Alessio DJ: Crosssectional study of recurrent herpes labialis. Am J Epidemiol 1988;127:612-625.

-2 Embil J, Stephens R, Manuel F: Prevalence of recurrent herpes labialis and aphthous ulcers among young adults on six continents. Can Med Assoc J 1975;113:627-630.

$>3$ Hwang C, Horsburgh B, Pelosi E, Roberts S, Digard P, Coen D: A net +1 frameshift permits synthesis of thymidine kinase from a drug-resistant herpes simplex virus mutant. Proc Natl Acad Sci USA 1994;91:5461-5465.

4 Wallace K, Khan M, Carlson R, Rice S, Froberg $\mathrm{M}$ : Cyclodextrin compositions and methods of treating viral infections. United States Patent Application Publication; Pub. No.: US 2003/0220294 A1; publication date: November 27, 2003.

$>5$ Bender F, Whitbeck J, Ponce de Leon M, Lou H, Eisenberg R, Cohen G: Specific association of glycoprotein B with lipid rafts during herpes simplex virus entry. J Virol 2003;77:95429552.
6 Graham D, Chertova E, Hilburn J, Arthur L, Hildreth J: Cholesterol depletion of human immunodeficiency virus type 1 and simian immunodeficiency virus with beta-cyclodextrin inactivates and permeabilizes the virions: evidence for virion-associated lipid rafts. J Virol 2003;77:8237-8248.

7 Rooney JF, Straus SE, Mannix ML, Wohlenberg CR, Alling DW, Dumois JA, et al: Oral acyclovir to suppress frequently recurrent herpes labialis: a double-blind, placebo-controlled trial. Ann Intern Med 1993;118:268272.

8 Irie T, Uekama K: Pharmaceutical applications of cyclodextrins. III. Toxicological issues and safety evaluation. J Pharm Sci 1997; 86:147-162.

$>9$ Baker D, Eisen D: Valacyclovir for prevention of recurrent herpes labialis: 2 double-blind, placebo-controlled studies. Cutis 2003;71: 239-242.

-10 Snipes W, Person S, Keller G, Taylor W, Keith A: Inactivation of lipid-containing viruses by long-chain alcohols. Antimicrob Agents Chemother 1977;11:98-104.
11 Sands J, Auperin D, Snipes W: Extreme sensitivity of enveloped viruses, including herpes simplex, to long-chain unsaturated monoglycerides and alcohols. Antimicrob Agents Chemother 1979;15:67-73.

12 Katz DH, Marcelletti JF, Khalil MH, Pope LE, Katz LR: Antiviral activity of 1-docosanol, an inhibitor of lipid-enveloped viruses including herpes simplex. Proc Natl Acad Sci USA 1991; 88:10825-10829.

13 Jakasa I, Verberk MM, Esposito M, Bos JD, Kezic S: Altered penetration of polyethylene glycols into uninvolved skin of atopic dermatitis patients. J Invest Dermatol 2007;127: 129-134.

14 Gilbert SC: Management and prevention of recurrent herpes labialis in immunocompetent patients. Herpes 2007;14:56-61.

15 Hull CM, Harmenberg J, Arlander E, Aoki F, Bring J, Darpo B, et al: Early treatment of cold sores with topical ME-609 decreases the frequency of ulcerative lesions: a randomized, double-blind, placebo-controlled, patientinitiated clinical trial. J Am Acad Dermatol 2011;64:696.e1-696.e11. 